\title{
The Self-Perceived Knowledge of Special Education Administrators in Kuwait
}

\author{
Zainab Abbas ${ }^{1}$, Hashemiah Almusawi ${ }^{1} \&$ Nouf Alenezi $^{1}$ \\ ${ }^{1}$ College of Basic Education, The Public Authority for Applied Education and Training, Kuwait \\ Correspondence: Zainab Abbas, College of Basic Education, The Public Authority for Applied Education and \\ Training, Kuwait.
}

Received: October 19, 2018

Accepted: November 27, 2018 Online Published: April 29, 2019

doi:10.5539/ies.v12n5p78

URL: https://doi.org/10.5539/ies.v12n5p78

\begin{abstract}
Administrators of special education identify and provide essential services for students with disabilities. No research has been conducted on the perceptions of Kuwait's special education administrators regarding their knowledge in key special education standard areas. This study examined those perceptions and the extent to which they are influenced by administrators' experience, qualification level, school district, or educational setting. Quantitative data were collected by surveying 62 special education administrators and were analyzed using descriptive statistics, a one-way ANOVA, and Spearman's rank-order correlations. The results indicated that the participants consider themselves most knowledgeable in two areas (1) collaboration and (2) leadership and policy - but less knowledgeable in the areas of research and inquiry, individual and program evaluation, and professional development and ethical practice. A significant relationship was found between self-assessment ratings and the educational setting where the administrator was working. Recommendations are made with the aim of enhancing the knowledge and development of special education administrators. The limitations of the study and further research possibilities are also discussed.
\end{abstract}

Keywords: CEC standards, knowledge, Kuwait, perceptions, special education administrators, students with disabilities

\section{Introduction}

Administrators of special education play an important role in identifying and providing useful services to students with disabilities. Isaac, Teresa, and Pemberton (2016) indicated that the role of special education administrators has undergone a paradigm shift toward evidence-based practices to improve outcomes for students with specific disabilities. A special education administrator's effectiveness is measured through his or her ability to inculcate, guide, assess, and evaluate teachers in their use of evidence-based practices, which in turn leads to improved educational outcomes (Boscardin, 2004). Lashley and Boscardin (2003) reported that special education administrators have become increasingly preoccupied with legal compliance, school reform, and accountability, which has resulted in a shift of focus from the responsibility of delivering effective interventions. They also found that most special education administrators who previously worked in direct special education services had a deep understanding of the assumptions, practices, and necessary knowledge in the field. Special education administrators are responsible for ensuring the rights of students with disabilities by advocating for quality school and classroom practices that can facilitate their educational success (Alquraini \& Gut, 2012).

Crockett, Becker, and Quinn (2009) reviewed 474 article abstracts about special education administration and leadership from the years 1970 to 2009. They concluded that the main factors affecting the work of special education leaders included collaboration between stakeholders, improved accountability measures in schools, and the growing use of technology. They also noted that in the area of leadership models and responsibilities, relatively few studies were based on data, as most of the articles contained non-research-based information in the form of professional commentaries. Collaborative leadership is the key to establishing teaching and learning processes that can best support achievement by students with disabilities (Murkuria \& Obiakor, 2006). Although effective leadership has a profound impact on student educational achievement (Tim, Marzano, \& McNulty, 2003), special education administrators often lack the requisite knowledge, skills, or experiences to function at a high performance level. Therefore, setting standards for special education administrators could help to enhance understanding of how leadership influences instructional practices (McEntyre \& Ostell, 2012). One widely used 
set of such standards is discussed in the following section.

\subsection{Special Education Administrator Standards}

The Council for Exceptional Children (CEC) stated in 2009 that the number of individuals delivering special education while lacking the appropriate preparation to do so had been increasing steadily since about 1993 . One mechanism that could help in understanding the influence of leadership on instructional practices and learning would be the use of educational leadership standards.

For this reason, the CEC (2009) developed a set of six standards for special education administrators at the advanced level. The first standard, Leadership and Policy, involves using knowledge of the history of special education, current legal and ethical standards, and emerging issues to fulfill leadership responsibilities. Among these responsibilities, special education administrators should advocate for appropriate educational policies and resources, and they should create positive and productive work environments.

The second standard, Program Development and Organization, focuses on improving instructional programs through the understanding and application of cognitive science, learning theory, and instructional technologies. This standard encourages special education administrators to coordinate educational standards with the needs of students with disabilities. Moreover, they should expand their understanding of instructional technologies, curriculum standards, effective teaching strategies, and assistive technologies to give students with disabilities greater access to learning opportunities.

Third, the Research and Inquiry standard calls for deep understanding of relevant models, theories, philosophies, and research methods to guide one's professional practice. Special education administrators should evaluate and apply educational research to improve their instructional techniques, interventions, and curricular materials.

The fourth standard is Individual and Program Evaluation, which encompasses the knowledge of theories and systems of educational assessment, as well as implementing evidence-based assessment practices. Special education administrators should rely on existing research to help them evaluate their school's instructional practices and assess progress toward meeting the school's goals and fulfilling its mission. Furthermore, they should apply their knowledge and skills to evaluate students with disabilities effectively.

Fifth, the Professional Development and Ethical Practice standard focuses on creating supportive environments for students with disabilities and their families. Lastly, the Collaboration standard recognizes the need for special education administrators to consult and collaborate effectively with others, as well as to draw on their knowledge to resolve conflicts and build consensus among students, educators, and families.

For more than 30 years, the $\mathrm{CEC}$ has established the validity of its standards through research and testing (Council of Exceptional Children, 2009). According to Boscardin, McCarthy, and Delgado (2009), these standards provide an essential framework that articulates the skills and knowledge that special education administrators need. The National Council for the Accreditation of Teacher Education has also approved this set of standards, which are consistent across the field of special education yet flexible in terms of content, context, and issues within various specialty areas.

Clifford (2016) investigated the degree to which experience, educational and professional preparation, and state certification influenced the effectiveness of 64 special education administrators with regard to meeting CEC standards. The results showed that the administrators' amount of experience had a significant impact on their understanding of the standards. Clifford found that most of the participants were strong in collaboration, ethical practices, laws, regulations, and policies, but relatively weak in diversity, technology, and evaluation models.

\subsection{The Special Education System in Kuwait}

Kuwait has been a pioneer in the Gulf region in serving individuals with disabilities ever since it passed its law entitled Care for the Handicapped (law number 49 of 1996), with the twofold intention of protecting the rights of individuals with disabilities and providing services to promote independence. A second, subsequent piece of legislation, called Rights of Individuals with Disabilities (2010), stipulates that these individuals must receive a free and appropriate education in a variety of educational levels and settings (Al-Hilawani, Koch, \& Braaten, 2008; Al-Hilawani, 2011).

Kuwait's special education system was planned to model Western policy and practice, primarily from the United States and the United Kingdom (Barr, 1983; Tanaka, 2005). Teachers can be hired by the Ministry of Education for special education administrative positions upon passing the required examination. They must have at least 14 years of teaching experience, complete a required evaluation of excellence for two years in their previous position, maintain a clear file in relationship to obeying civil laws, pass the written exam and personal interview, and 
complete and pass the Ministry of Education's preparatory workshops (Ministry of Education, 2007).

Administrators play numerous essential roles in serving students with disabilities. They must provide the necessary leadership in guiding and monitoring the delivery of services (Almuhareb, 2007), which can occur in three different educational settings (although the special education administrator's role is essentially the same in all of them). The least seclusive of these three settings is mainstream schools, in which students with learning disabilities are taught within general education classrooms. Kuwait also has special-needs schools, where students with disabilities are taught separately from typical students, and inclusion schools, where they are educated in the same schools as regular students but in separate classrooms.

However, many administrators in Kuwait have no experience in dealing with students with disabilities in an inclusive setting, as they usually either come from outside the field of special education or have delivered special education in a segregated manner where special education students are taught separately. This lack of experience often leads to a gap between the administrators' job performance and currently recommended best practices in the field, as administrators tend to adopt practices that they are familiar with, rather than using new practices that would require substantial adaptations (Almuhareb, 2007).

It appears, therefore, that special education administrators in Kuwait may have insufficiently clear standards to guide their work. Consequently, the overarching research question driving this study is to determine the perceptions of special education administrators regarding the standards that govern their responsibilities. From this main question, three sub-questions arise that will be used as a guide for the study analyses:

(1) To what extent do special education administrators believe that they are knowledgeable across the six areas addressed in the CEC standards?

(2) Is there a relationship between the administrators' number of years of experiences and their responses to the survey questions?

(3) Is there a difference in self-assessment ratings between the administrators based on the qualification level they have attained or the educational setting where they serve?

\subsection{Problem}

Prior to this study, there were no data regarding special education administrators' knowledge of special education standards in Kuwait. Therefore, this study sought to determine that information and to analyze whether administrators' knowledge was related to other variables such as their extent of experience, qualification level, or educational setting. We also analyzed the distribution of other variables, such as gender, educational background, and school district.

\subsection{Significance of the Study}

Acquiring data about the perceptions of Kuwaiti special education administrators could help those responsible for special education quality to gain insights as to the administrators' needs and ways to improve education for exceptional children. The findings of this study could also identify issues in special education administration that merit further research.

\section{Method}

The data collection method was an online survey distributed to administrators using Google Forms. The aim of survey research in education is to enable researchers to answer questions, solve problems, assess needs, analyze trends across time, and describe and quantify existing opportunities (Fowler, 2014). Because of the nature of the research question, we used a nonrandomized survey design. To analyze the data, we applied quantitative methods including statistical descriptive analyses, a one-way ANOVA, and Spearman's rank-order correlation analyses. Further analysis, such as the post-hoc Scheffé test, was performed to identify significant differences between pairs of means (Lomax \& Hahs-Vaughn, 2012). To conduct our analysis, we used the Statistical Package for the Social Sciences (SPSS, version 22.0).

\subsection{Participants}

The population in this study consisted of Kuwaiti special education administrators working under the Ministry of Education. Kuwait has six school districts: Alasema, Alahmadi, Aljhara, Hawally, Alfarwanya, and Mubarak Alkabeer. In each school district, there are two elementary and two middle-level inclusion schools (one for boys and one for girl at each level). Special-needs schools are located mainly in the Hawally district, and there are four mainstream schools (two elementary and two middle-level) in the Mubarak Alkabeer district.

The sample for this study was drawn from special education administrators across the three different educational 
settings. Each school has three or four administrators, making a total of 145 special education administrators across Kuwait. Due to this limited number, random sampling was not necessary. Instead, all special education administrators were invited to complete the survey; 62 of whom responded, and all responses were suitable for inclusion in the analysis. Table 1 provides descriptive statistics on the sample.

\subsection{Material}

The survey was based on the CEC's Preparation Standards: Advanced Administrator of Special Education Specialist Set. These standards were first adopted in 2009 and then updated in 2012 and again in 2015 (Council of Exceptional Children, 2015). The CEC standards were chosen for several reasons. First, they have been validated by the CEC through research and testing over a 30-year period (Council of Exceptional Children, 2009). Second, questions based on the Advanced Administrator of Special Education Specialist Set standards can help us to better understand how leadership impacts instructional practices and student learning (McEntyre \& Ostell, 2012). Third, the Kuwaiti special education system has been heavily influenced by Western models (Barr, 1983; Tanaka, 2005), so an investigation using the CEC standards should be appropriate for this particular system.

The survey questions asked participants to rate their knowledge in each area covered by the CEC's special education standards. The survey was divided into two sections. The first section consisted of demographic variables, including gender, educational background, and school district. The second section contained 38 questions, designed to evaluate the participants' self-reported knowledge of items under all six CEC standards. Ratings were given on a 3-point Likert scale, with choices of "very knowledgeable," "somewhat knowledgeable," and "not knowledgeable." We chose to use a simple scale so that the participants could easily rate their knowledge and to reduce potential confusion (Matell \& Jacoby, 1972).

\subsection{Validity}

Prior to the study, three faculty members from the College of Basic Education in Kuwait were asked to review the survey and consider the validity of the questions by determining whether they actually measured what they were intended to measure. The three reviewers all held Ph.D. degrees in special education and had extensive backgrounds in the special education field. In response to their suggestions, slight adjustments were made to some questions.

\subsection{Data Collection}

Approval from Kuwait's Ministry of Education was obtained prior to the initiation of the data collection process. We then disseminated the survey through a message sent to the participants' phone numbers. This message explained the purpose of the study and included a link to the online survey. We sent follow-up messages one week later, either to thank participants for responding or to encourage them again to complete the survey if they had not already done so. As noted above, 62 of 145 respondents completed the survey, for a response rate of $42.7 \%$.

\section{Results}

Among the respondents, $79.0 \%$ reported that a bachelor's degree was the highest academic degree they had attained; 9.7\% had attained the diploma level, a master's degree was the highest for $8.1 \%$, and $3.2 \%$ held a doctorate. Overall experience levels were quite high, with $17.7 \%$ reporting more than 30 years of experience (counting years of teaching as well as administration), $30.6 \%$ reporting 26 to 30 years, and another $27.4 \%$ at 21 to 25 years. Less than one-fourth of all respondents had 20 years of experience or less (16.1\% at 16 to 20 years, $8.1 \%$ at 15 years or fewer).

The gender balance among participating administrators was uneven, with $69.4 \%$ females and $30.6 \%$ males. The great majority (77.4\%) was licensed in general education and only $14.5 \%$ in special education; the remaining $8.1 \%$ were specialists in other relevant disciplines.

The 62 respondents were working at 22 different schools. Table 1 presents their responses by school district, educational stage (i.e., the age level of students at their school), and educational setting among the three types of special education delivery modes. 
Table 1. Response rate by school district, educational stage and educational setting

\begin{tabular}{llll}
\hline Characteristic & & Number & Percentage \\
\hline \multirow{4}{*}{ School District } & Hawally & 33 & 53.2 \\
& Alasema & 8 & 12.9 \\
& Alfarwanya & 8 & 12.9 \\
& Mubarak Alkabeer & 7 & 11.3 \\
& Alahmadi & 6 & 9.7 \\
\hline \multirow{3}{*}{ Educational Stage } & Kindergarten & 5 & 8.1 \\
& Primary schools & 29 & 46.8 \\
& Middle schools & 28 & 45.2 \\
& Secondary schools & 3 & 4.8 \\
\hline \multirow{3}{*}{ Educational Setting } & Mainstream schools & 43.5 & 27 \\
& Special-needs schools & 43.5 & 27 \\
& Inclusion schools & 12.9 & 8 \\
\hline
\end{tabular}

Of Kuwait's six school districts, one of them (Al-jahra) provided no responses and thus was excluded from the study. On the other hand, the Hawally district, which has the largest number of special-needs schools, was responsible for more than half of all respondents. The participating schools ranged across all age groups from kindergarten to secondary schools, but the great majority was primary schools (29) or middle schools (28). The participating schools were mostly mainstream or special-needs schools (27 each), with 8 responses coming from inclusion schools.

The responses were analyzed with regard to administrators' self-reported competencies in 38 knowledge areas, within the six overall standards, that the CEC has identified as imperative for the special education profession. Responses were also analyzed by respondents' school district, educational setting, number of years of experience (classified into five ranges), and qualification level (diploma, bachelor's degree, master's degree, doctorate).

Concerning the first research question (To what extent do special education administrators believe that they are knowledgeable across the six areas addressed in the CEC standards?), the data suggest that special education administrators generally viewed themselves as having a moderate level of knowledge and rarely perceived themselves as lacking knowledge in any of the six CEC standard areas. They reported being very knowledgeable most frequently in two areas: Collaboration as well as Leadership and Policy. In contrast, they ranked themselves as having the lowest level of knowledge in the area of Research and Inquiry, followed by Individual and Program Evaluation. The most commonly reported knowledge level was "somewhat knowledgeable," with more than half of all replies falling into this category on all six standards except Collaboration. Table 2 reports the knowledge levels reported by special administrators on each standard.

Table 2. Special education administrators' self-reported CEC knowledge levels

\begin{tabular}{llccc}
\hline & CEC Standard & Very Knowledgeable & Somewhat Knowledgeable & Not Knowledgeable \\
\hline 1 & Leadership and Policy & 44.4 & 52.0 & 3.6 \\
2 & Program Development and Organization & 40.9 & 53.7 & 5.4 \\
3 & Research and Inquiry & 22.6 & 62.9 & 14.6 \\
4 & Individual and Program Evaluation & 32.3 & 54.8 & 12.9 \\
5 & Professional Development and Ethical Practice & 36.3 & 53.0 & 10.7 \\
6 & Collaboration & 44.5 & 48.7 & 6.8 \\
& Total & 36.8 & 54.2 & 9.0 \\
\hline
\end{tabular}

Responses were further analyzed by individual statement. The highest percentage of respondents rating themselves as very knowledgeable (62.9\%) occurred on each of three statements: (a) under Leadership and Policy, the statement "Emerging issues and trends that potentially affect the school community and the mission of the school"; (b) under Program Development and Organization, the statement "Effects of the cultural and environmental milieu of the individual and the family on behavior and learning"; and (c) under Individual and Program Evaluation, the statement "Evaluate a student's success in the general education curriculum."

On the other hand, the highest percentages of "not knowledgeable" replies were given on these three statements: (a) $25.8 \%$ on "Adult learning theories and models as they apply to professional development programs" under 
Professional Development and Ethical Practice; (b) $21.0 \%$ on "Research in administrative practices that support individuals with exceptional learning needs and their families" under Research and Inquiry; and (c) $17.7 \%$ on "Variety of methods for assessing and evaluating individuals with exceptional learning needs' performance" under Individual and Program Evaluation.

To answer the second research question, on the relationship between the special administrators' knowledge level of the CEC standards and their years of experience, these two variables were compared using Spearman's rank-order correlation analysis. The result indicated no significant relationship between the two variables (Spearman's rho $=.078, p<0.05$ ).

Finally, two series of one-way ANOVA analyses were run to answer the third research question, as to whether there was a difference in the self-assessment ratings based on the administrators' qualification level or educational setting. The analysis by qualification level revealed no significant effect $(F(3,58)=.532, p=.66)$. On the other hand, a significant effect of educational setting was revealed $(F(2,59)=6.737, p=.002)$. A post-hoc Scheffé test was performed to find out which pairs of means were significantly different. The results showed that the level of CEC knowledge among special administrators in special-needs schools $(M=2.47, S D=.32)$ was statistically higher than that for administrators in inclusion schools $(M=2.22, S D=.32)(F(2,59)=9.564, p<.05)$ and also higher than the knowledge level among administrators in mainstream schools $(M=2.08, S D=.27)(F(2,59)=$ $8.449, p<.05)$.

\section{Discussion}

To the best of our knowledge, this is the first study that explicitly examined Kuwaiti special education administrators' perceptions of their knowledge related to the CEC standards. The conclusions derived from the responses to the survey are summarized below.

The first research question explored participants' knowledge in each of the six CEC standard areas. The standard area in which the greatest percentage of participants described themselves as "very knowledgeable" was Collaboration, paralleling a strength identified among special education administrators by Clifford (2016). This result is also consistent with Crockett et al. (2009), whose review of article abstracts indicated that collaboration between special education administrators and other stakeholders strongly impacted the administrators' leadership skills.

Indeed, special education administrators should have extensive knowledge with regard to collaboration, as it is essential to bridge the gaps between general and special education as well as to provide appropriate educational programs for students with disabilities (Boscardin, 2007). Mukuria and Obiakor (2006) stated that collaborative leadership is "the key ingredient without which very little can be achieved in any school setting" (p. 13).

The standard areas ranking second and third, in terms of the percentage of administrators rating themselves as highly knowledgeable, were Leadership and Policy, and Program Development and Organization.

On the other hand, only $22.55 \%$ of participants reported that they were very knowledgeable regarding the Research and Inquiry standard area, $32.26 \%$ about the Individual and Program Evaluation standard area, and $36.27 \%$ on Professional Development and Ethical Practice. These low ratings suggest that these are the three standard areas needing the greatest attention among special education administrators in Kuwait. Administrators should have an understanding of models, theories, and research methods to help them guide and improve their professional practice, and they should be able to evaluate students with disabilities effectively. All these areas can be improved through professional development (CEC, 2009).

Regarding the second research question, we anticipated that we would find a relationship between the administrators' amount of experience and their responses to the survey questions. However, there was no significant correlation. This result was inconsistent with Clifford (2016), who found that special education administrators with 11 or more years of experience had a significantly greater understanding of the CEC standards than administrators with less experience. However, it is possible that the relatively weak statistical power of our analysis, based on the fairly small number of participants, affected this finding of non-significance.

With regard to the third research question, we found a relationship between self-assessment ratings and the educational setting where the administrator was working. A post-hoc Scheffé test showed that participants working in special-needs schools had a stronger knowledge of the standards than those serving in mainstream and inclusion schools. The results of this study seem aligned with the perspective of Lashley and Boscardin (2003), who concluded from their literature review that special education administrators who worked most extensively with special education students tended to possess the deepest knowledge of the field. Administrators employed in special-needs schools generally work only with special education students and their teachers. In addition, the 
Ministry of Education requires all types of schools to provide training workshops for teachers and administrators. This ongoing training requirement might offer a further advantage for those administrators who work in special-needs schools, as they would be consistently attending workshops that focus primarily on special education, enabling them to continue to strengthen their expertise in this area.

\section{Limitations, Further Studies, and Recommendations}

We recommend that stakeholders in Kuwait, such as leaders in the Ministry of Education, district administrators, and policymakers, work together to enhance the knowledge of special education administrators by providing educational workshops and training. These education opportunities should be concentrated on the three areas where administrators gave the lowest ratings of their own knowledge (i.e., Research and Inquiry, Individual and Program Evaluation, and Professional Development and Ethical Practice). The Ministry of Education should adopt standards to guide the training and services it provides to special education administrators. Furthermore, it is recommended that Kuwait University and Kuwait's College of Basic Education develop courses or programs specifically for special education administrators, to enhance their knowledge and leadership capacities.

Although we distributed our survey to all special education administrators in Kuwait, the response rate may not allow for generalization even within the country. Another limitation is that the study's design, data collection, and analyses were quantitative in nature. Qualitative research could explore in greater detail the actual knowledge level of special education administrators with regard to the specialized standards pertinent to their field. In-depth observational analyses would also yield greater understanding of these administrators' skills. Moreover, it would be useful to examine the relationship between special education administrators' knowledge and skills and the educational achievements of students with disabilities in their schools. Such studies could further guide the development of special education administrators in Kuwait.

\section{References}

Al-hilawani, Y. A. (2011). The lost Kuwait initiative: The failure has come from within. The Journal of International Special Needs Education, 14(1), 40-48.

Al-hilawani, Y. A., Koch, K. R., \& Braaten, S. R. (2008). Enhancing services for students with mild disabilities in the Middle East Gulf Region: A Kuwait Initiative. TEACHING Exceptional Children Plus.

Almuhareb, K. A. (2007). Characterizing the current state of education of individuals with disabilities in Kuwait: Developing a baseline for reflection and action. University at Buffalo. Retrieved from http://hdl.handle.net/10477/42714

Alquraini, T., \& Gut, D. (2012). Critical components of successful inclusion of students with severe isabilities: Literature review. International Journal of Special Education, 27(1), 42-59. http://doi.org/EJ979712

Barr, J. H. (1983). Education for the handicapped in the Arabian Peninsula: Issues and trends. Colombia University Teachers College.

Boscardin, M. L. (2004). Transforming administration to support science in the schoolhouse for students with $\begin{array}{lllll}\text { disabilities. Journal of } & \text { Learning }\end{array}$ https://doi.org/10.1177/00222194040370031201

Boscardin, M. L., McCarthy, E., \& Delgado, R. (2009). An integrated research-based approach to creating standards for special education leadership. Journal of Special Education Leadership, 22(2).

Clifford, J. B. (2016). Proficiency of special education administrators on CEC standard. University of Wyoming. Retrieved from https://repository.uwyo.edu/edd $/ 2 \% 0 \mathrm{~A} \% 0 \mathrm{~A}$

Council for Exceptional Children. (2009). What every special educator must know. America. http://doi.org/10.1111/j.1558-5646.2011.01242.x/abstract

Council for Exceptional Children. (2015). What every special educator must know: Professional ethics \& standards (7th ed.). Arlington.

Crockett, J. B., Becker, M. K., \& Quinn, D. (2009). Reviewing the knowledge base of special education leadership and administration from 1970-2009. Journal of Special Education Leadership, 22(2).

Fowler, F. J. (2014). Survey Research Methods (5th ed.). London: SAGE Publications, Inc.

Hahs-Vaughn, D. L., \& Lomax, R. G. (2012). An Introduction to Statistical Concepts (3rd ed.). New York: Routledge.

Issac, J., Starrett, T. M., \& Pamperton, J. (2016). Special education administrators' perceptions of responsibilities 
and challenges. International Journal of Learning, Teaching and Educational Research, 15(7), 1-19.

Lashley, C., \& Boscardin, M. L. (2003). Special education administration at a crossroads: Availability, licensure, and preparation of special education administrators. Center on Personnel Studies in Special Education.

Matell, M. S., \& Jacoby, J. (1972). Is there an optimal number of alternatives for Likert-scale items? Effects of testing time and scale properties. Journal of Applied Psychology. http://doi.org/10.1037/h0033601

McEntyre, J., \& Ostell, J. (2012). Expanding the Leadership Framework. In Handbook of Leadership and Administration for Special Education. Abingdon: Routledge. http://doi.org/10.4324/9780203837313.ch3

Mukuria, G., \& Obiakor, F. E. (2006). Beyond Narrow Confines: Special Education Leadership for Ethnically Diverse Urban Learners. Educational Considerations, 34(1), 9-15. Retrieved from https://doi.org/10.4148/0146-9282.1195

Tanaka, M. (2006). The cross-cultural transfer of educational concepts and practices: A comparative study. Comparative and General Pharmacology. http://doi.org/10.1086/510059

Tim, W., Marzano, R. J., \& McNulty, B. (2003). Balanced Leadership ${ }^{\text {TM }}$ : What 30 years of research tells us about the effect of leadership on student achievement. McREL Working Paper, 5(21). http://doi.org/10.1080/09243450512331383272

\section{Copyrights}

Copyright for this article is retained by the author(s), with first publication rights granted to the journal.

This is an open-access article distributed under the terms and conditions of the Creative Commons Attribution license (http://creativecommons.org/licenses/by/4.0/). 